\title{
Prolonged exposure to transdermal nicotine improves memory in male mice, but impairs biochemical parameters in male and female mice
}

\author{
Barbara Nieradko-Iwanicka ${ }^{1, A-F}$, Dorota Pietraszek ${ }^{2, B}$, Katarzyna Pośnik ${ }^{2, B}$, Andrzej Borzęcki ${ }^{1, F}$ \\ ${ }^{1}$ Chair and Department of Hygiene Medical University of Lublin, Poland \\ 2 Students' Scientific Association at the Chair and Department of Hygiene, Medical University, Lublin, Poland \\ A - Research concept and design, B - Collection and/or assembly of data, C - Data analysis and interpretation, \\ $D$ - Writing the article, E-Critical revision of the article, $F$ - Final approval of article
}

\begin{abstract}
Nieradko-Iwanicka B, Pietraszek D, Pośnik K, Borzęcki A. Prolonged exposure to transdermal nicotine improves memory in male mice, but
\end{abstract} impairs biochemical parameters in male and female mice. Ann Agric Environ Med. 2019; 26(1): 62-66. doi: 10.26444/aaem/89599

\begin{abstract}
Introduction. Nicotine is an alkaloid that affects the functioning of the central nervous system and produces dependence. In low doses, it acts as a stimulant and relaxant. Nicotine was reported to have pro-cognitive effects in humans and animals. However, high doses of nicotine are harmful for many organs.The aim of the study was to check whether a 30-day exposure to transdermal nicotine affects memory and biochemical parameters in mice.

Materials and method. A total of 32 mice (16 males and 16 females) were used in the experiment. Mice were divided into 4 groups of 8 animals each: I control-females receiving placebo patches for 30 days, II females receiving nicotine patches for 30 days, III control-males receiving placebo patches, IV males receiving nicotine patches. Spontaneous alternation and locomotor activity were examined weekly in a Y-maze. Body mass was recorded daily. On day 30, venous blood samples were obtained and the animals were anaesthetized with $\mathrm{CO}_{2}$. Their blood was used to measure alanine transaminase (ALT), asparagine transaminase (AST), cholesterol, creatinine and glycosylated haemoglobin ( $\mathrm{HbA} \mathrm{C}_{1}$ ).

Results. Nicotine significantly improved memory in male mice on day 8. It increased ALT and AST activities in males and females, as well as the concentration of cholesterol in their blood sera.

Conclusions. In conclusion, transdermal nicotine may produce transient improvement in fresh spatial memory in male mice, but it is not a long-term effect and therefore nicotine does not seem to be appropriate for use in the treatment of neurodegenerative disorders. It elevates blood cholesterol level and thus may increase the risk of atherosclerosis and cardiovascular events; moreover, it negatively affects liver enzymes. Nicotine use is therefore not recommended.
\end{abstract}

Key words

memory, biochemical parameters, nicotine

\section{INTRODUCTION}

Nicotine is an alkaloid found in the nightshade family of plants. Nicotine in low doses acts as a stimulant and relaxant, but high doses can be harmful [1] because it produces psychopharmacological effects by activating the nicotinic acetylcholine receptors ( $\mathrm{AAChR}$ ) that are normally activated by the endogenous acetylcholine (ACh) [2]. The widespread expression of $\mathrm{nAChR}$ throughout the nervous system accounts for the wide variety of effects produced by nicotine. Nicotine has a crucial influence on the synaptic mechanisms of learning and also contributes to the addiction process [3]. Nicotine directly and indirectly activates midbrain dopamine neurons and causes dopamine release [3]. Nicotine is highly addictive and the addiction drives tobacco use by one billion people worldwide, causing nearly six million deaths a year, as nicotine is harmful to all internal organs [4]. Nicotine abuse is associated with cardiovascular disease [5], maternal toxicity and potential birth defects [6], cancer [7] and poisoning [8].

Address for correspondence: Barbara Nieradko-Iwanicka Medical University of Lublin, Radziwiłłowska 11, 20-080 Lublin, Poland

e-mail: bnieradkoiwanicka@wp.pl

Received: 14.11.2017; accepted: 28.03.2018; first published: 11.05.2018
The metabolism of nicotine in mice is very similar to that in humans; therefore, mice are considered to be good models for experiments with the use of nicotine. It is expected that they mirror the effects in humans $[9,10]$.

Nicotine-releasing patches are used in nicotine replacement therapy [11]. Transdermal bioavailability of nicotine is estimated to be $68 \%$. After absorption, nicotine is distributed with the blood, and blood rich in nicotine stimulates the release of $\mathrm{ACh}$, norepinephrine, adrenaline and dopamine $[12,13,14]$. This release of neurotransmitters and hormones is responsible for psychoactive effects of nicotine. Nicotine causes the release of glucose from the liver and adrenaline from the adrenal medulla, which is how it produces the stimulating effect in users. In high doses, nicotine is toxic. Most cases of poisoning with nicotine occur after exposure to tobacco products [8], gum or patches. Workers who cultivate, harvest, or handle tobacco may experience green tobacco sickness, caused by dermal absorption of nicotine [15].

As the elderly population grows worldwide, there is a rise in the number of people suffering from age-related memory impairment. The pro-cognitive effects of tobacco in the elderly have been of great interest to many researches $[16,17]$. 


\section{OBJECTIVE}

The aim of the study was to observe the behavioural and biochemical features of mice exposed to transdermal patches releasing nicotine at the dose of $0.12 \mathrm{mg} / 24 \mathrm{~h}$ for 30 subsequent days.

\section{MATERIALS AND METHOD}

All the experimental procedures were conducted with respect for the legal regulations of the European Community, including Poland. They were conducted in the Laboratory of Behavioural Studies at the Animal Quarters of the Medical University in Lublin, Poland. The Local Ethics Committee for Animal Experiments in Lublin approved the experiment (Opinion No. 8/2015, dated 23 January 2015). The experiments were performed between 08:00 - 18:00 in standard laboratory conditions.

Albino Swiss mice weighing 18-24 g and approximately 6 weeks old were purchased from a licensed breeder (J. Kołacz, Wilga, Warsaw, Poland) for use in the study. All animals were given a 7-day acclimation period and maintained on a $12 \mathrm{~h}$ light/dark cycle. Food and tap water were provided ad libitum. The colony room was maintained at $21 \pm 2^{\circ} \mathrm{C}, 50 \pm 10 \%$ relative humidity on a 12-hour-light/-dark cycle (lights on at 07:00). Thirty-two animals were used in the experiment.

Mice were randomly divided into 4 groups of 8 mice:

- Control females receiving sham patches and handled in the same way as tested mice.

- Females receiving transdermal nicotine patches releasing $0.12 \mathrm{mg}$ of nicotine $/ 24 \mathrm{~h}$.

- Control males receiving sham patches and handled in the same way as tested mice,

- Males receiving transdermal nicotine patches releasing $0.12 \mathrm{mg}$ of nicotine $/ 24 \mathrm{~h}$. The nicotine patches were attached at the base of the tails of the mice.

Nicotine in the form of patches releasing $21 \mathrm{mg}$ of nicotine per 24 hours (NiQuitin21 mg/24h. Step 1; GlaxoSmithKline) used for nicotine replacement therapy (NRT) was used. Every day, a new patch was cut into pieces containing $0.12 \mathrm{mg}$ of nicotine and the scraps were placed at the base of mice tail once daily for 30 consecutive days. The piece of patch was protected with adhesive tape used in dressing wounds each time after application.

The animals were tested in a Y-maze. Spontaneous alternation in a Y-maze is considered as a measure of spatial working memory [18]. The mice were individually placed in the Y-maze consisting of 3 compartments measuring $10 \times 10$ $\mathrm{x} 10 \mathrm{~cm}$ at the angle of $120^{\circ}$. The Y-maze had no floor and each time it was placed on a clean sheet of paper on a table top in order to prevent odour clues. Alternation (defined as consecutive entries into all 3 sections without repetitions) was scored. The percent alternation was calculated as the ratio of actual possible alternations (defined as the total number of section entries -2 ) x 100 . The ability to alternate requires that the mice remember which sections have previously been visited. Therefore, spontaneous alternation is regarded as a measure of spatial working memory [18].

The number of arm entries is also a measure of locomotor activity. Spontaneous alternation and locomotor activity were examined in a Y-maze on days 1, 8, 15, 22 and 29.
Body mass was recorded daily. On day 30, venous blood samples were obtained and the animals anaesthetized with $\mathrm{CO}_{2}$. Their blood was used to measure the activity of alanine transaminase (ALT), asparagine transaminase (AST), concentration of cholesterol, creatinine and glycated haemoglobin $\left(\mathrm{HbA}_{1} \mathrm{C}\right)$.

The results obtained were shown as means \pm SEM, and evaluated by one-way analysis of variance ANOVA followed by Dunnett's test. The $\mathrm{p}$ value $<0.05$ was considered statistically significant.

\section{RESULTS}

Nicotine did not significantly affect locomotor activity in mice (Fig.1), but significantly improved fresh spatial memory in male mice on day 8 (Fig. 2). The mean percentage of logical alternations in male mice exposed to transdermal nicotine on day 8 was $92 \%$, compared to $44 \%$ in control males $(\mathrm{p}<0.05)$. Nicotine did not affect the rate of weight gain in the experimental animals (Fig. 3); however, it produced an increase in the activities of AST (Fig. 4) and ALT (Fig. 5) in the blood sera. The mean ALT concentration in the sera of female mice exposed to nicotine was by $58 \%$ higher than in controls $(\mathrm{p}<0.05)$, while the mean AST in females exposed to nicotine was $167 \mathrm{U} / 1$, compared to $88 \mathrm{U} / \mathrm{l}$ in controls $(\mathrm{p}<0.05)$. Nicotine did not significantly affect the concentration of creatinine (Fig. 6) in mice blood sera, but significantly increased the concentration of total cholesterol (Fig. 7) in the blood sera of both female and male mice. Mean concentrations of total cholesterol were: $86 \mathrm{mg} / \mathrm{dl}$ in females exposed to nicotine compared to $64 \mathrm{mg} / \mathrm{dl}$ in controls and $97 \mathrm{mg} / \mathrm{dl}$ in males, compared to $65 \mathrm{mg} / \mathrm{dl}$ in controls, respectively $(\mathrm{p}<0.05)$. Nicotine did not significantly affect the level of $\mathrm{HbA}_{1} \mathrm{C}$ (Fig. 8) in mice.

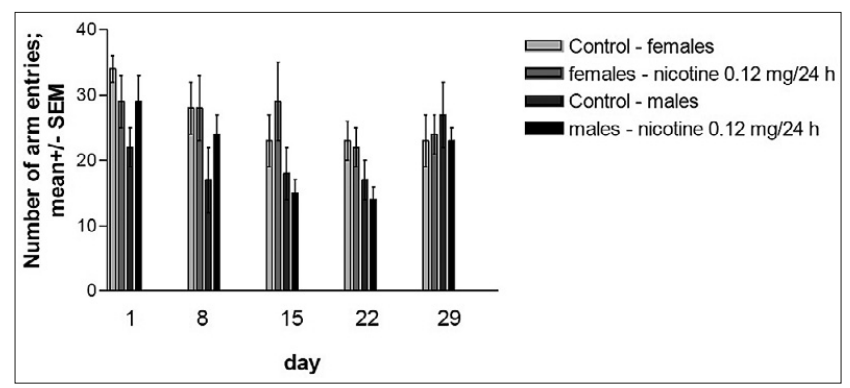

Figure 1. Locomotor activity measured in the Y-maze within $8 \mathrm{~min}$

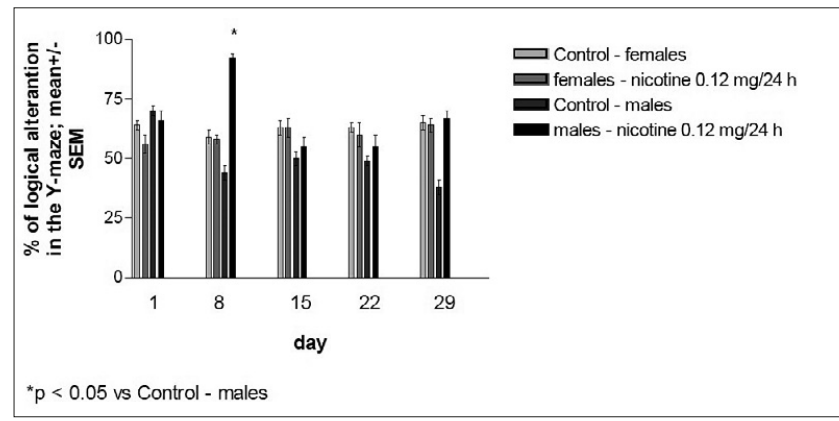

Figure 2. Fresh spatial memory in the $Y$-maze 


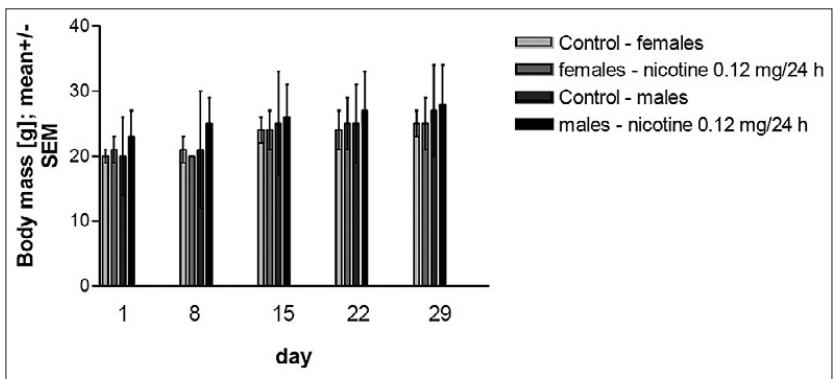

Figure 3. Body mass gain during the study

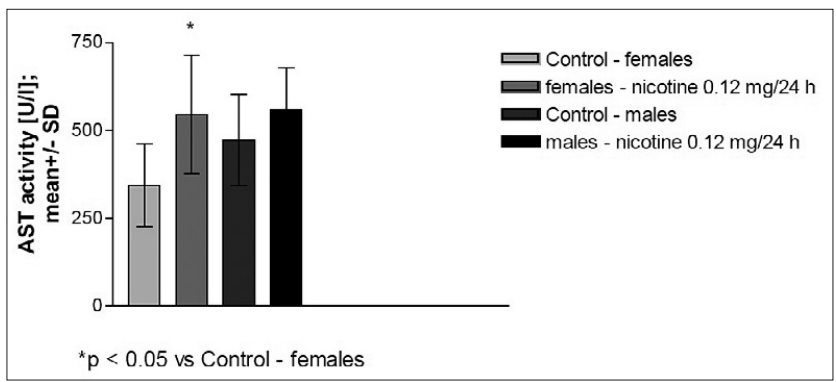

Figure 4. AST activity in the blood sera

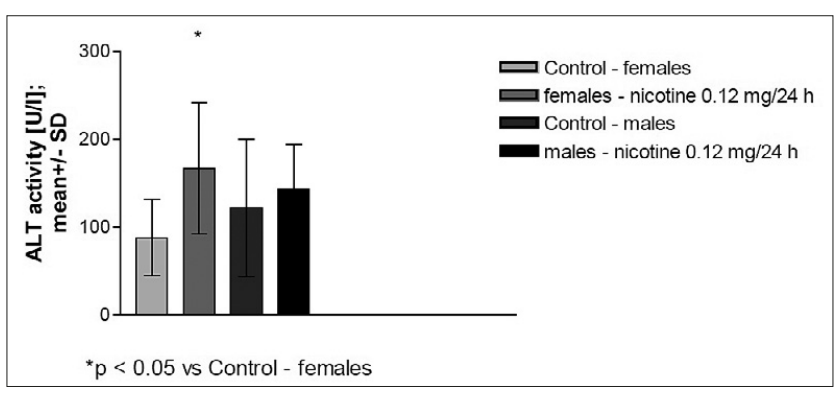

Figure 5. ALT activity in the blood sera

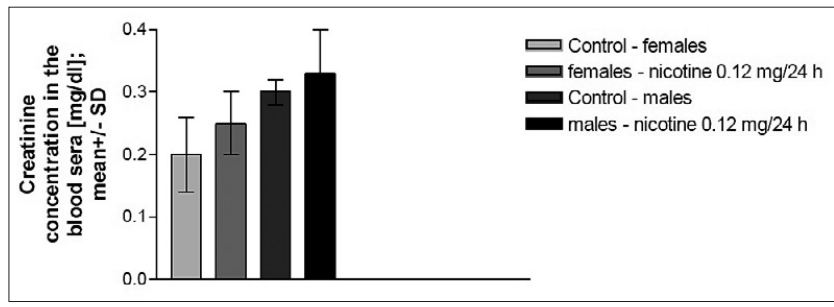

Figure 6. Creatinine concentration in the blood sera

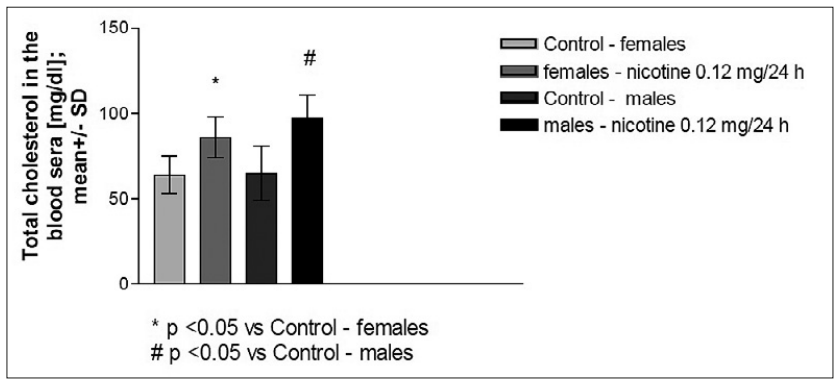

Figure 7. Total cholesterol concentration in the blood sera

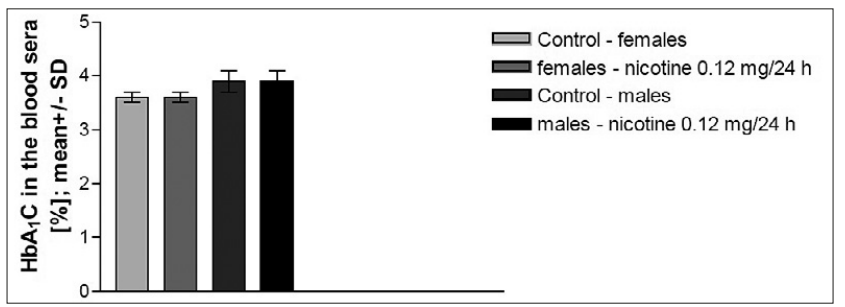

Figure 8. $\mathrm{HbA} 1 \mathrm{C}$ concentration in the blood

\section{DISCUSSION}

In the presented study, the dose of $0.12 \mathrm{mg} / 24 \mathrm{~h}$ nicotine was chosen to produce a model of subacute poisoning in the experimental poisoning. The fact was taken into consideration that the range of toxic doses of nicotine is very wide: according to Szymańska et al. nicotine's $\mathrm{LD}_{50}$ by gavage in different animals ranges from $3.34-199 \mathrm{mg} / \mathrm{kg} / \mathrm{bw}$ for humans $0.5-1 \mathrm{mg} / \mathrm{kg} / \mathrm{bw}$, but there were cases of survival after ingestion of $4 \mathrm{~g}$ [10]. Dermal dosage is less common; however, it is worth noting because nicotine patches are recommended in the treatment of nicotine dependence. As has been reported, dermal exposure of humans to toxic doses of nicotine occurs during the picking and drying of nicotiana tabacum leaves (green tobacco sickness), spraying nicotine as a pesticide or after accidental use by children. If we compared the dose of nicotine/kg bw from nicotine patch used in the treatment of nicotine dependence for a human with an average body mass of $70 \mathrm{~kg}$ to the dose used in the present study in mice, it would be $21 \mathrm{mg}$ nicotine $/ 70 \mathrm{~kg}$ human bw/day, compared to $0.12 \mathrm{mg} / 20 \mathrm{~g}$ of mice bw/day. Therefore, the dose used for experimental animals was 20 times higher than the dose recommended for humans during nicotine replacement therapy. As underlined in the literature, human exposure to nicotine stimulates atherosclerosis and cardiovascular disease in males. We wanted to mimic the effect during an experiment of 30-day duration in which an increase in cholesterol level in mice blood sera was expected [10]. Nicotine is metabolized in a very similar way in mice and humans [9]. The metabolism takes place in the liver via $\mathrm{C}$-oxidation, demetylation and C-oxydation, $\mathrm{N}$-oxydation or N-metylation [10]. The main metabolites are cotinine and nicotin-1'N-oxide which are excreted with urine [10]. In the presented study, ALT, AST and creatinine were also measured. Moreover, the liver is an organ of key importance for lipid and carbohydrate metabolism; therefore, $\mathrm{HbA}_{1} \mathrm{C}$ and cholesterol were additionally measured. As the main effects of nicotine action are in the nervous system, a behavioural test was performed.

Nicotine at high doses acts on the $\mathrm{nAChR}$ in the skeletal muscles producing muscle fibrillation and paralysis [19]. In this study, the dose ( $0.12 \mathrm{mg}$ of nicotine/ $24 \mathrm{~h}$ ) was so low that it did not affect the level of locomotor activity of the mice. On the other hand, the dose used was high enough to produce pro-cognitive effect in the male mice on day 8 . This can be explained by the fact that nicotine has a higher affinity for $\mathrm{nAChRs}$ in the brain than those in skeletal muscle [1]. On days 15, 22 and 29 the \% of logical alternation in male mice exposed to nicotine was still higher than in male controls, but the differences were not statistically significant. This may have been due to developing tolerance to the drug. 
Nicotine is known to have a pro-cognitive effects on the central nervous system by acting as an agonist for $\mathrm{nAChRs}$. Due to its short half-life (2-6h) [20], high toxicity (oral LD in mice $3.3-24 \mathrm{mg}$ nicotine $/ \mathrm{kg}$ of body mass; in rats, $50-$ $188 \mathrm{mg} / \mathrm{kg}$ ) and high potential for producing addiction there is a discussion among scientists whether it could be used as a pro-cognitive drug in humans [10]. Since cholinergic neurotransmission plays a major role in cognition, stimulation of the nAChR may be a target for cognitive enhancement. While nicotine is believed to improve performance in several cognitive domains, the results of individual studies vary. A possible explanation for these findings is that the effect of nicotine administration may be dependent on baseline cognitive function, where subjects with a suboptimal cognitive performance may benefit from nicotine, while subjects who already perform optimally may show a decline in performance after nicotinic stimulation [21]. This theory is supported by the study of Seidl et al. who investigated the effect of nicotine administered transdermally (5 mg transdermal patches) on cognitive performance in adult humans with Down's syndrome. They recorded significant improvements in information processing [22]. Several studies have shown that nicotine use may help to improve cognitive deficits in the population of schizophrenia patients [23, 24], especially because as much as $72-90 \%$ of this population smoke cigarettes [25].

In the presented study, at baseline males had better memory than females, despite the fact that it was the male mice which demonstrated the pro-cognitive effect of nicotine on day 8 . This may be because the mice were not suffering from any disease or were exposed to nicotine before the experiment. According to Newhouse et al., healthy individuals are unlikely to show cognitive benefits after nicotinic stimulation, except under extreme task conditions [26].

As the human population is ageing, scientists hope that transdermal nicotine could be effective in the treatment of neurodegenerative diseases. Noshita et al., showed that nicotine ameliorated learning and memory deficits in rats injected with amyloid, which is mediated by the enhancement of cholinergic neurotransmission. The ligands of nAChR, including nicotine, are thought to be useful as a treatment for Alzheimer's disease [27]. This theory is supported by the results obtained by other authors. According to Li et al., who conducted a study on rats receiving nicotine orally and intravenously, cotinine - the major metabolite of nicotine - is a potential pro-cognitive agent and could be a potential therapeutic in Alzheimer's disease [28]. The effect of transdermal nicotine on behaviour was studied by Evans et al. [29]. The authors noticed that nicotine administration facilitated and nicotine deprivation reduced cognitive control in smokers. Importantly, nicotine effects on cognition reinforced smoking behaviour, especially among individuals who had cognitive deficits. A $7 \mathrm{mg}$ nicotine patch failed to enhance neural indices of cognitive control among nonsmokers in that study [29].

Nicotine is metabolized in the liver. Although Robinson and Whitehead showed only a weak effect of exposure to nicotine on the liver function in humans, they underlined that nicotine increased $\gamma$-glutamyl transferase (GGT). However, their study concerned only human male subjects [30]. In the presented study, exposure to nicotine was shown to increase the activities of AST and ALT in mice blood sera, which showed that prolonged exposure to nicotine might damage the liver. The results are in agreement with those obtained in the study by Fahim et al. who injected mice with nicotine at the dose of $1 \mathrm{mg} / \mathrm{kg}$ of body mass intraperitoneally for 21subsequent days. They recorded a significant rise in ALT and AST activities [31].

Nicotine and its metabolites are excreted with urine [32]; therefore, it was decided in the current study to asses kidney function in the experimental animals by measuring creatinine level in their blood sera. It was shown that nicotine did not affect creatinine concentration in mice blood sera. Other studies, however, show that cigarette smoking leads to the progression of chronic kidney disease, especially in diabetic patients [33].

Whether nicotine leads to a persistent increase in blood glucose levels is not clear. According to Szymańska et al., rat exposure to nicotine at a total dose of $315 \mathrm{mg}$ over 90 days, or at a cumulative dose of $359 \mathrm{mg}$ over 28 days, produced a serious dysregulation in the lipid and carbohydrate levels in the blood sera [10]. According to Ashakumary et al., female rats exposed to nicotine at the dose of $3.5 \mathrm{mg} / \mathrm{kg}$ for 90 days by gavage increased total cholesterol concentration, and phospholipid and triglycerides concentration in their blood sera [34]. Glycated haemoglobin $\left(\mathrm{HbA}_{1} \mathrm{C}\right)$ or glycated albumin can be used as a markers of glycaemia in diabetes and vascular complications [35]. In the current study, the dose of nicotine used did not affect the rate of weight gain or affect the level of $\mathrm{HbA}_{1} \mathrm{C}$ in mice.

According to Mc Culloch et al., smoking is associated with a decrease in body weight in patients without diabetes mellitus, and an increase in insulin resistance and haemoglobin $\mathrm{HbA}_{1} \mathrm{C}$ levels in patients with type 1 diabetes mellitus [36]. Nicotine is known to reduce the appetite and increase metabolism; therefore, many smokers lose weight. Whether smoking is associated with an increase in $\mathrm{HbA}_{1} \mathrm{C}$ and/or a decrease in body mass index (BMI) in type 2 diabetes mellitus is unresolved, however. In the study by Clair et al. it was shown that the presence of nicotine metabolite cotinine in the body is associated with increased $\mathrm{HbA}_{1} \mathrm{C}$ in the population without diabetes [37]. McCulloch et al. studied the effect of smoking on $\mathrm{HbA}_{1} \mathrm{C}$ levels and BMI in a cross-section of outpatients with type 2 diabetes mellitus [36]. The results obtained in their study suggest that smoking does not have a significant direct effect on $\mathrm{BMI}$ or $\mathrm{HbA}_{1} \mathrm{C}$ in patients with type 2 diabetes mellitus. The authors suggest that the relationship between these factors is much more complex than in people without diabetes, or in patients with type 1 diabetes mellitus.

In the current study, the exposure to nicotine resulted in a significant elevation of cholesterol concentration in mice blood sera. On one hand, high blood cholesterol strongly increases the risk of thromboembolic injury [31], while on the other hand, Elahy et al. found that nicotine moderately protects the blood brain barrier (BBB) integrity. They used an established mouse model of BBB disruption induced by a diet enriched in saturated fatty acids (SFA).The authors concluded that nicotine moderately attenuated $\mathrm{BBB}$ disruption induced by chronic ingestion of high-SFA diet, but had no significant effect on neuroinflammation [38].

The problem of exposure to tobacco and its consequences for health is extremely important in Eastern European countries, especially in Poland, Hungary and Romania, as in these countries the percentage of female smokers is as high as $40 \%$. As a consequence, Poland and other central European countries have the highest mortality from lung cancer in 
women, compared to other countries. The correlation between tobacco smoking and the development of lung cancer has been well known since $1970[4,39]$.

Despite authors' intention to record as many behavioural and biochemical effects of transdermal nicotine on the experimental animals as possible, numerous limitations caused by financial restrictions prevented full imvestigation. The authors therefore plan to continue their work on nicotine.

\section{CONCLUSIONS}

Transdermal nicotine may produce transient improvement in fresh spatial memory in male mice, but it is not a long-term effect; therefore, nicotine does not seem to be appropriate for use in the treatment of neurodegenerative disorders. It elevates the blood cholesterol level and thus may increase the risk of atherosclerosis and cardiovascular events. Nicotine also negatively affects liver enzymes. All in all, the use of nicotine is not recommended.

\section{REFERENCES}

1. Benowitz NL, Hukkanen J, Jacob P,III. Nicotine chemistry, metabolism, kinetics and biomarkers. Handb Exp Pharmacol 2009; 92: 29-60.

2. Harrington L, Viñals X, Herrera-Solís A, Flores A,Morel C, Tolu S, et al. Role of $\beta 4^{*}$ nicotinic acetylcholine receptors in the habenulointerpeduncular pathway in nicotine reinforcement in mice. Neuropsychopharmacology. 2015 Nov 20. doi: 10.1038/npp.2015.346. [Epub ahead of print]. cited 23.11.2015.

3. Subramaniyan M, Dani JA. Dopaminergic and cholinergic learning mechanisms in nicotine addiction. Ann N Y Acad Sci. 2015; 1349(1): 46-63.

4. Ezzati M, Riboli E. Behavioral and dietary risk factors for noncommunicable diseases. N Engl J Med. 2013; 369 (10): 954-64.

5. Leone A, Landini L Jr, Biadi O, Balbarini A. Smoking and cardiovascular system: cellular features of the damage. Curr Pharm Des. 2008; 14(18): 1771-7.

6. Feng JH, Yan YE, Liang G, Liu YS, Li XJ, Zhang BJ, Chen LB, Yu H, He $\mathrm{XH}$, Wang $\mathrm{H}$. Maternal and fetal metabonomic alterations in prenatal nicotine exposure-induced rat intrauterine growth retardation. Mol Cell Endocrinol. 2014; 394(1-2): 59-69.

7. Sanner T, Grimsrud TK. Nicotine: Carcinogenicity and Effects on Response to Cancer Treatment - A Review. Front Oncol. 2015; 5: 196 doi: 10.3389/fonc. 2015.00196

8. Bassett RA, Osterhoudt K, Brabazon T. Nicotine Poisoning in an Infant N Engl J Med. 2014; 370: 2249-50.

9. Raunio H, Pokela N, Puhakainen K, Rahnasto M, Mauriala T, Auriola $\mathrm{S}$, Jovonen RO. Nicotine metabolism and urinary elimination in mouse: in vitro and in vivo. Xenobiotica 2008; 38 (1): 34-47.

10. Szymańska JA, Frydrych B, Bruchajzer E. Nikotyna dokumentacja dopuszczalnych wielkości narażenia zawodowego. Podstawy i Metody Oceny Środowiska Pracy 2007; 2 (52): 121-154.

11. Yingst JM, Veldheer S, Hrabovsky S, Sciamanna C, Foulds J. Reasons for non-adherence to nicotine patch therapy during the first month of a quit attempt. Int J Clin Pract. 2015; 69(8): 883-8.

12. Gould TJ, Prescott PT. Cellular, molecular, and genetic substrates underlying the impact of nicotine on learning. Neurobiol Learn Mem. 2014; 107: 108-32.

13. Larsson A, Engel JA. Neurochemical and behavioral studies on ethanol and nicotine interactions. Neurosci Biobehav Rev. 2004; 27(8): 713-20.

14. Zaniewska M, Mc Creary AC, Wydra K, Faron-Gorecka A, Filip $\mathrm{M}$. Context-controlled nicotine-induced changes in the labeling of serotonin (5-HT) 2A and 5-HT 2C receptors in the rat brain. Pharm Rep 2015; 67: 451-459.

15. Klaassen CD, Watkins III JB. Casarett \&Doull's Essentials of Toxicology. $2^{\text {nd }}$ ed. New York: McGraw-Hill2010 [chapter 22].
16. Swan GE, Lessov-Schlaggar CN. The effects of tobacco smoke and nicotine on cognition and the brain. Neuropsychol Rev. 2007; 17(3): 259-73.

17. Leibovici D, Ritchie K, Ledesert B, Touchon J. The effects of wine and tobacco consumption on cognitive performance in the elderly: a longitudinal study of relative risk. Int J Epidemiol. 1999; 28(1): 77-81.

18. Sarter M, Bodewitz G, Stephens DN. Attenuation of scopolamineinduced impairment of spontaneous alternation behavior by antagonist but not inverse agonist and agonist $\beta$-carbolines. Psychopharmacology 1988; 94: 491-5.

19. Klaassen CD, Watkins III JB. Casarett \&Doull's Essentials of Toxicology. $2^{\text {nd }}$ ed. New York: McGraw-Hill 2010 [chapter 3].

20. Hukkanen J, Jacob P, III, Benowitz NL. Metabolism and disposition kinetics of nicotine. Pharmacol Rev. 2005; 57: 79-115.

21. Niemegeers P, Dumont GJ, Quisenaerts C, Morrens M, Boonzaier J, Fransen E, et al. The effects of nicotine on cognition are dependent on baseline performance. Eur Neuropsychopharmacol. 2014; 24(7): 1015-23.

22. Seidl R, Tiefenthaler M, Hauser E, Lubec G. Effects of transdermal nicotine on cognitive performance in Down's syndrome. Lancet 2000; 356 (9239): 1409-10.

23. AhnAllen CG, Bidwell LC, Tidey JW. Cognitive effects of very low nicotine content cigarettes, with and without nicotine replacement, in smokers with schizophrenia and controls. Nicotine Tob Res. 2015; 17(5): 510-4.

24. Wing V, Sacco K, George T. Spatial working memory impairments induced by cigarette smoking abstinence are correlated with plasma nicotine levels in schizophrenia. Schizophrenia Res. 2011; 128 (1-3): $171-2$.

25. Gupta T, Mittal VA. Nicotine usage is associated with elevated processing speed, spatial working memory, and visual learning performance in youth at ultrahigh-risk for psychosis. Psychiatry Res. 2014; 220(1-2): 687-90.

26. Newhouse PA, Potter A, Singh A. Effects of nicotinic stimulation on cognitive performance. Curr Opin Pharmacol. 2004; 4(1): 36-46.

27. Noshita T, Murayama N, Murayama S. Effect of nicotine on neuronal dysfunction induced by intracerebroventricular infusion of amyloid- $\beta$ peptide in rats. Eur Rev Med Pharmacol Sci. 2015; 19(2): 334-43.

28. Li P, Beck WD, Callahan PM, Terry AV, Bartletta MG. Pharmacokinetics of cotinine in rats: A potential therapeutic agent for disorders of cognitive function. Pharm Rep. 2015; 76(3): 494-500.

29. Evans DE, Jentink KG, Sutton SK, Van Rensburg KJ, Drobes DJ. 7 mg nicotine patch fails to enhance P300 neural indices of cognitive control among nonsmokers. Pharmacol Biochem Behav. 2014; 126: 77-82.

30. Robinson D, Whitehead P. Effect of body mass and other factors on serum liver enzyme levels in men attending for well population screening. Ann Clin Biochem. 1989; 26: 393-400.

31. Fahim MA, Nemmar A, Al-Salam S, Dhanasekaran S, Shafiullah M, Yasin J, Hassan MY. Thromboembolic injury and systemic toxicity induced by nicotine in mice. Gen Physiol Biophys. 2014; 33(3): 345-55.

32. Goodman and Gilman's the pharmacological basis of therapeutics. Hardman J G Ed. 9. ed. New York, Mc Graw-Hill, 1996:192.

33. Hua P, Feng W, Ji S, Raij L, EA. Nicotine worsens the severity of nephropathy in diabetic mice: implications for the progression of kidney disease in smokers. Am J Physiol Renal Physiol. 2010; 299(4): 732-39.

34. Ashakumary L, Vijayammal PL. Effect of nicotine on lipoprotein metabolism in rats. Lipids. 1997; 32(3): 311-315.

35. Warwas M, Żurawska-Płaksej E, Ciężka D, Piwowar A. Glycated albumin as a marker of glycemia in diabetes and its vascular complications; Postepy Hig Med Dosw. 2015; 69: 638-48. [Article in Polish].

36. McCulloch P, Lee S, Higgins R, McCall K, Schade DS. Effect of smoking on hemoglobin Alc and body mass index in patients with type 2 diabetes mellitus. J Investig Med. 2002; 50(4): 284-7.

37. Clair C, Bitton A, Meigs JB, Rigotti NA. Relationships of cotinine and self-reported cigarette smoking with hemoglobin A1c in the U.S.: results from the National Health and Nutrition Examination Survey, 1999-2008. Diabetes Care 2011; 34(10): 2250-5.

38. Elahy M, Lam V, Pallebage-Gamarallage MM, Giles C, Mamo JC, Takechi R. Nicotine attenuates disruption of blood-brain barrier induced by saturated-fat feeding in wild-type mice. Nicotine Tob Res. 2015; 17(12): 1436-41.

39. Kaleta D, Fronczak A. Disparities in exposure to tobacco smoke pollution at Romanian worksites. Ann Agric Environ Med. 2015; 22(4): 755-761. 